„Kwartalnik Filmowy” nr 112 (2020)

ISSN: 0452-9502 (Print) ISSN: 2719-2725 (Online)

https://doi.org/10.36744/kf.454

(c) Greative Commons BY-NC-ND 4.0

Pawel Sitkiewicz

Uniwersytet Gdański

https://orcid.org/oooo-0003-2039-9154

\title{
Jak datować początek polskiej animacji? Śledztwo filmoznawcze
}

\author{
Slowa kluczowe: \\ polska animacja; \\ polski film \\ animowany; \\ kino polskie; \\ początki animacji
}

\begin{abstract}
Abstrakt
Artykuł nawiązuje do obchodów 55-, 60- i 70-lecia polskiej animacji, organizowanych w latach 2004, 2007 i 2017. Autor stara się odpowiedzieć na podstawowe pytania: kiedy właściwie zaczyna się historia polskiej animacji? Dlaczego w refleksji historycznej pomija się okres przedwojenny? W tym celu omawia dziesięć najpopularniejszych kryteriów, którymi posługują się historycy kina na całym świecie, opisując genezę animacji w swoich krajach. Wszystkie kryteria zostają dopasowane do polskich warunków kulturowych i produkcyjnych, a także zestawione z filmami zrealizowanymi w latach 1917-1957. W efekcie autor proponuje rewizję jubileuszy organizowanych od $2004 \mathrm{r}$. Jednocześnie stara się zrozumieć racje tych historyków, którzy twierdzą, że początek polskiej animacji stanowi premiera lalkowego filmu za króla Krakusa Zenona Wasilewskiego z 1947 r.
\end{abstract}


Podobno wszystko zaczęło się od filmu Zenona Wasilewskiego Za króla Krakusa z 1947 r. Ta premiera odcisnęła się głęboko w historii polskiego kina. Zgodnie z nią organizowano obchody kolejnych rocznic: 55-, 60- i 70-lecia polskiej animacji. Towarzyszyły im publikacje naukowe i prasowe, projekcje kinowe, programy telewizyjne i wystawy. Ale każdą rocznicę zakłócała natrętna myśl, że korzeni polskiej animacji należy szukać nie 70 ani 80, lecz nawet 100 lat temu.

Postanowiłem sprawdzić, jak było w rzeczywistości. Ktoś zapyta, czy gra jest warta świeczki. Przecież jubileusze mają głównie znaczenie marketingowe lub branżowe, nie muszą iść w parze z badaniami filmoznawców. Jednak wydaje się, że to kwestia istotna. Pytanie o początki to jedno z fundamentalnych zadań historii kina. Rocznice powinny ponadto odzwierciedlać wiedzę historyczna, nie mogą być arbitralne. Wreszcie tytułowe pytanie ma pomóc w zrozumieniu argumentacji tych, którzy mimo wszystko uważają że początki animacji w Polsce wyznacza premiera Za króla Krakusa. Dodatkowo chciałbym zbadać, w jaki sposób datuje się początki różnych zjawisk w światowym kinie animowanym, aby polskie spory ukazać na szerokim tle dyscypliny, a zwłaszcza - najnowszych badań.

Sprawdzian chciałbym rozpocząć od tezy, która równie dobrze mogłaby być wnioskiem: nie istnieje jedno obiektywne kryterium, na podstawie którego można wyznaczyć „punkt zero” w dziejach jakiejkolwiek kinematografii narodowej. W historii kina animowanego dostrzegam aż dziesięć kryteriów, które chciałbym punkt po punkcie omówić, a następnie pokazać, w jaki sposób stosowano je w polskim środowisku filmowym (tu od razu trzeba zaznaczyć, że nie wszystkie występują w pojedynkę i często łączą się w pary lub trójkąty). To zaś powinno ułatwić nam odpowiedź na tytułowe pytanie.

Kryteria brzmią następująco. „Punkt zero” wyznaczać może:

1) manifest, idea lub patent;

2) pierwszy istniejący ślad filmowy (zachowany lub niezachowany);

3) pierwszy zachowany film (kompletny);

4) pierwszy film fabularny/fikcjonalny;

5) pierwszy film zrealizowany na ziemiach (historycznie) polskich;

6) pierwszy film zrealizowany przez polskiego twórcę;

7) pierwszy film zrealizowany w niepodległej Polsce;

8) pierwszy dystrybuowany film;

9) pierwszy profesjonalny film;

10) symboliczny początek lub pierwsze sukcesy artystyczne.

Na marginesie chciałbym zauważyć, że kryteria te uwzględniają odrębność filmu animowanego i na pewno nie odnoszą się do wszystkich rodzajów filmowych. Jak słusznie pisze Eva Strusková o trudnościach związanych z badaniem początków animacji czechosłowackiej: film animowany bardzo różnił się od filmu fabularnego czy dokumentalnego, przede wszystkim dlatego, że rozwijat się głównie poza strukturami komercyjnej branży filmowej. Wycinanki, kreskówki i filmy lalkowe powstawaty przeważnie w warunkach domowych, w mieszkaniach $i$ małych studiach, a jedynymi pomocnikami i poplecznikami [pionierów] byli członkowie rodziny ${ }^{1}$. Uwaga ta w równym stopniu odnosi się do polskiego kina, niezależnie od tego, gdzie ustalimy „punkt zero" na osi czasu. 


\section{Kryterium 1.: manifest, idea lub patent}

Film animowany przez wiele dekad powstawał wyłącznie za pomocą technik poklatkowych, będących przeciwieństwem zapisu „na żywo” (live action), dlatego był i jest postrzegany jako odrębne zjawisko w rodzinie sztuk filmowych. Można przyjąć, że „punkt zero" to wynalezienie tej specyficznej techniki, udokumentowane w manifeście, patencie lub opisane we wspomnieniach. Kryterium to wydaje się kontrowersyjne, ponieważ eksponuje sam pomysł, a nie twórczość. Mimo to bywa zaskakująco często stosowane. Antologia Roberta Russetta i Cecile Starr, która odegrała ważną rolę w kodyfikacji kanonu animacji eksperymentalnej, swoją właściwą narrację zaczyna od Leopolda Survage'a, czyli twórcy, który co prawda nie zrealizował żadnego filmu, ale w latach 1912-1914 napisał ważny tekst teoretyczny i zaprojektował film, który nigdy nie trafił na ekrany. Survage zostaje nazwany „prekursorem animacji abstrakcyjnej”, który za sprawą manifestów i szkiców koncepcyjnych wymyślit pomost pomiędzy malarstwem i filmem². Zgodnie z tą samą logiką za patrona animacji uchodzi czasami Georges Méliès. Choć brakuje dowodów, że posługiwał się techniką animacji poklatkowej, bywa on uznawany za kogoś, kto jako pierwszy „postrzegał kino jako królestwo wyobraźni”. Wyświetlanie filmów Mélièsa przypomina dziś oglądanie filmu animowanego... bez animacji ${ }^{3}$ - pisał Giannalberto Bendazzi.

Podobną argumentację stosuje Malcolm Cook w książce na temat początków animacji brytyjskiej. Zwraca bowiem uwagę, że sceniczne lightning sketches, polegające na występie komika-ilustratora, który rysował na tablicy szkicowe rysunki - to tak naprawdę pionierskie filmy animowane, mimo iż ich twórcy przez wiele lat w ogóle nie posługiwali się medium filmowym, a jeżeli nawet - to początkowo bez użycia techniki poklatkowej. Pionierzy lightning sketches - pisze Cook - byli jednymi z pierwszych grafików, którzy wykorzystali ruchome obrazy. Co więcej, błyskawiczna karykatura stała się wzorem dla wszystkich artystów, którzy chcieli nadać performatywny i czasowy wymiar swym wcześniej statycznym pracom. (...) btyskawiczna karykatura antycypuje animacje filmowa, uwydatniając takie właściwości, jak transformacja, ruch rysunków kreskowych oraz pragnienie ożywienia rysunków ${ }^{4}$. To zaś pozwala mu wyznaczyć początek brytyjskiej animacji w 1895 r., gdy po raz pierwszy zarejestrowano te występy sceniczne na taśmie, a nie - jak czyni większość historyków - w 1899 r., kiedy powstały pierwsze poklatkowe filmy Arthura Melbourne-Coopera. To oznacza, że dla wielu kompetentnych badaczy kina animowanego liczy się idea, a nie konkretna technika.

W wypadku polskich pionierów również można zastosować Kryterium 1. Feliks Kuczkowski, dziennikarz i malarz amator, wpierw „wynalazł” animację, którą nazwał „filmem wizyjnym”, a dopiero potem zrealizował filmy - dalekie zresztą od postulowanej idei sztuki totalnej, będącej syntezą literatury, filozofii oraz sztuk plastycznych. Jak czytamy w jego wspomnieniach: Film wizyjny narzucit mi się w roku 1916, w dziwacznym transie malarskim, w interesującym psychologicznie napięciu natchnień i pasji plastyki (... $)^{5}$. Postanowił więc tę ideę ożywić. 


\section{Kryterium 2.: pierwszy istniejący ślad filmowy (zachowany lub niezachowany) Kryterium 3.: pierwszy zachowany film (kompletny)}

To kryteria najczęściej stosowane. Każdy odnaleziony film lub fragment taśmy może zmienić podręcznikową wiedzę. Czasami wystarczą wiarygodne relacje pisemne, a nie zachowane filmy, choć niektórzy historycy domagają się bardziej namacalnych "dowodów na istnienie", wychodząc z założenia, że wspomnienia bywają kłamliwe, wzmianki w prasie enigmatyczne, a opisy w katalogach filmowych - zbyt zdawkowe. Niech za ilustrację posłuży spór o Humpty Dumpty Circus Jamesa Stuarta Blacktona i Edwarda Alberta Smitha z 1898 r., który uchodził kiedyś za mocnego kandydata na pierwszy film animowany w historii, ale - jak pisał Donald Crafton - najwyraźniej nie przetrwał. Nie ma też żadnej dokumentacji potwierdzajacej, $\dot{z}$ e kiedykolwiek istniat'. Jedyny dowód to wspomnienia samego Smitha.

Istnieje pokusa, by to Kryterium 3. uznać za jedyne obiektywne i najbardziej sprawiedliwe, ale nawet tu pojawiają się wątpliwości. Odnalezienie najstarszego filmu i wpisanie go w kontekst historyczny z pomocą źródeł i aparatu naukowego nie zamyka procesu dowodowego. Najlepszym przykładem kulisy sporu wokół osiągnięć Arthura Melbourne-Coopera. Ati Mul i Tjitte de Vries wykonali tytaniczną pracę, by przywrócić należną mu rangę pioniera, czego efektem licząca 500 stron książka. Choć ich argumentacja brzmi przekonująco, nadal kwestionuje się podstawowy fakt, czyli rok premiery Apelu zapatek (Matches Appeal, 1899). To oznacza, że sam film to za mało. Trzeba jeszcze przekonać opinię publiczna, spopularyzować efekt badań. Dystans czasowy sprawia, że zawsze pozostają nieścisłości, dzięki którym można wznowić proces. Donald Crafton we wstępie do wspomnianej książki pisze o wrodzonym sceptycyzmie środowiska naukowego, które niechętnie przyjmuje rewelacyjne teorie, zwłaszcza gdy burzą utrwalony porządek ${ }^{7}$.

Kierując się Kryterium 2. (w połączeniu z 5. lub 6.), początków polskiej animacji można szukać przed 1918 r. W 1910 r. Władysław Starewicz, syn powstańca styczniowego mieszkający w Kownie, nakręcił swój pierwszy test animacji lalkowej, walkę żuków jelonków. Z kolei na przełomie 1916 i 1917 r. Feliks Kuczkowski - równorzędny pretendent do roli najważniejszego pioniera - zrealizował swój pierwszy krótki film: Flirt krzesełek (rysunki przygotował w Krakowie Lucjan Kobierski, sfilmowane zostały w Wiedniu). W obu wypadkach dowodem są teksty wspomnieniowe i wywiady, ponieważ filmy znamy tylko z rekonstrukcji oraz pojedynczych kadrów ${ }^{8}$. Zgodnie z Kryterium 3. i 6. byłby to pierwszy zachowany film Starewicza: Piękna Lukanida (Priekrasnaja Lukanida, 1911), dystrybuowana od marca 1912 r. Wątpliwości może budzić to, że film wyprodukowano dla kinematografii rosyjskiej, na dodatek w Kownie, a więc mieście o żywiole litewskim, a nie polskim, ale problem ten spróbuję rozwiązać w dalszej części tekstu. Gdyby zaś przyjąć Kryterium 3. i 7., musielibyśmy historię polskiej animacji rozpocząć od któregoś z anonimowych filmów reklamowych. W dwudziestoleciu międzywojennym wszyscy pionierzy, m.in. Kuczkowski, Wasilewski, Włodzimierz Kowańko i Jan Jarosz, zajmowali się produkcją reklam, a kilka z nich, w tym jedna fabularna, Czar Atlantydy Kowańki dla firmy Herbewo, przetrwało wojenną zawieruchę. 
O tym, że Kryterium 2. bywa kłopotliwe, świadczy niepełna wiedza na temat ostatniego z ważnych pionierów polskiej animacji - Stanisława Dobrzyńskiego. Dzięki jego prasowym wspomnieniom wiemy, że podobno już w 1918 r. zrealizował swój pierwszy film rysunkowy, Sen paskarza, ale niestety - nie da się zweryfikować, jakich użyto technik animacji, jak długa była to produkcja ani czy na pewno film istniał i czy nie był na przykład trikowy (moim zdaniem to prawdopodobne) $)^{9}$. Sam komentarz w prasie, bez fotosów, recenzji oraz relacji bezstronnych świadków, to za mało, by organizować jubileusz.

Najstarszy wizualny ślad (a nie tylko pisany) z okresu dwudziestolecia międzywojennego według mojego rozeznania pochodzi dopiero z 1931 r. Są to werki z planu oraz zdjęcia marionetek do filmu J. Michałowskiego, B. Mroczkowskiego i S. Żyszkowskiego, którzy pracę nad nim rozpoczęli rzekomo w marcu 1929 r. ${ }^{10}$ Nie znamy niestety tytułu. Początek lat 30. okaże się istotny również w wypadku innych kryteriów.

Obrońcy stanowiska, że początki polskiej animacji należy datować od 1947 r., również opierają się na Kryterium 3., wychodząc z założenia, że o przedwojennych pionierach nie można powiedzieć nic pewnego, gdyż ich twórczość nie zachowała się. Nie jest to odosobniony przypadek. Pierwsze pełnometrażowe filmy animowane w historii kina, autorstwa Quirino Cristianiego, znamy wyłącznie z relacji prasowych i pojedynczych kadrów, skutkiem czego za właściwych pionierów uchodzą często Lotte Reiniger, a nawet Walt Disney - tylko dlatego, że ich filmy ocalały do czasów dzisiejszych.

\section{Kryterium 4.: pierwszy film fabularny/fikcjonalny}

Odnoszę wrażenie, że historycy kina czują opór, by w obrębie kinematografii narodowych datować początki animacji od reklamówek lub ruchomych diagramów. Wolą nobilitować filmy fabularne, autorskie lub oparte na strukturze narracyjnej. Jak pisał Gunnar Strøm na temat początków animacji w krajach nordyckich, całkiem sporo uwagi poświęcono dumnej historii duńskich filmów rysunkowych. Jednak, podobnie jak w większości krajów, nacisk położono na wyświetlane w kinach filmy krótko- i petnometrażowe. Bogata i fascynujaca historia animowanych reklam z lat 20., nie wspominając już o wykorzystaniu animacji w obrazach dokumentalnych, kronikach, filmach przemysłowych i edukacyjnych, jest prawie zapomniana ${ }^{11}$. Strøm proponuje więc nowy sposób pisania historii kina animowanego. Skrupulatnie odnotowuje marginalne, a nawet chałupnicze produkcje, na przekór powszechnej opinii, że symboliczny początek nordyckiej animacji to sukces serii Victora Bergdahla o przygodach Kapitana Grogga.

Na ten sam problem zwraca uwagę Aleksander Deriabin, badając początki animacji w Związku Radzieckim. Przypomina, że „ożywione” poklatkowo mapy i diagramy z kronik Dzigi Wiertowa z 1918 r., a nie narracyjne Sowieckie zabawki (Sowietskije igruszki) z 1924 r., były chronologicznie pierwsze - a więc to one wyznaczają "punkt zero" w dziejach animacji sowieckiej, mimo że odznaczają się niskim stopniem profesjonalizmu, ciąży na nich odium eksperymentalnych wprawek, a także trudno dopasować je do właściwej twórczości Wiertowa z tego okresu ${ }^{12}$.

Nie zmienia to faktu, że w zbiorowej pamięci, której "twardym dyskiem” jest Internet, obecne są wyłącznie filmy fabularne - i to im poświęca się niemal 
całą uwage $\mathrm{w}$ historii kina oraz $\mathrm{w}$ trakcie jubileuszowych projekcji. Postawy Strøma i Deriabina należą do wyjątków.

Najstarsze animacje fabularne powstały w Polsce przed 1945 r. W zależności od kryterium należałoby wyróżnić albo Piękna Lukanidę (Kryterium 4. i 6.), albo Flirt krzesetek (Kryterium 4. i 5.), albo dystrybuowane w 1934 r. trzy filmy narracyjne: Pana Twardowskiego Włodzimierza Kowańki, Kwiat paproci Karola i Marty Marczaków oraz Przygody Puka Jana Jarosza (Kryterium 2., 4. i 7.). Na Kryterium 4. opiera się po części logika obchodów 55-, 60- i 70-lecia polskiej animacji. Animowane wstawki w obrębie filmów dokumentalnych i propagandowych, realizowane m.in. przez Zdzisława Lachura, Macieja Sieńskiego i Zenona Wasilewskiego, powstały przed premierą Króla Krakusa, ale od zawsze były marginalizowane w dyskursie filmoznawczym.

\section{Kryterium 5.: pierwszy film zrealizowany na ziemiach (historycznie) polskich Kryterium 6.: pierwszy film zrealizowany przez polskiego twórce Kryterium 7.: pierwszy film zrealizowany w niepodległej Polsce}

Są to trzy kryteria pomocnicze, nigdy bowiem nie występują samodzielnie.

I wojna światowa zmieniła mapę Europy. Na gruzach dawnych imperiów powstały nowe państwa, a zarazem potem wyłoniły się nowe kinematografie. Istnieją przesłanki, by początki polskiej animacji, tak samo jak początki polskiego kina, datować dopiero od 1918 r. Takie podejście wydaje się sprzeczne z szeroko pojętą tradycją humanistyki akademickiej, która nauczyła nas traktować sztukę powstałą w okresie zaborów jako polska, o ile dzieło było wykonane w języku polskim, przez polskiego twórcę, na ziemiach historycznie polskich, a zwłaszcza gdy wyraża treści patriotyczne lub odwołuje się do polskich dziejów. Dlatego twórczość Adama Mickiewicza i Fryderyka Chopina instynktownie zaliczymy do polskiej kultury, ale już w wypadku Josepha Conrada, a zwłaszcza Dymitra Szostakowicza (syn powstańca styczniowego) - mechanizm ten automatycznie nie zadziała. Jeszcze więcej kontrowersji budzą filmy, zwłaszcza gdy studio, kapitał i łańcuch dystrybucji znajdują się w obcych rękach. Produkcja i rozpowszechnianie filmów podlega bowiem mechanizmom instytucji kinematograficznej, której często nie da się oddzielić od struktur państwowych.

Władysław Starewicz przez całe życie czuł się Polakiem (mówił i pisał po polsku), co zgodnie potwierdzają jego biografowie, ale filmy kręcił dla kinematografii rosyjskiej, a następnie francuskiej i niemieckiej. Współpraca z polską kinematografią nigdy nie doszła do skutku, a jego filmy - jak udało mi się ustalić były w przedwojennej Polsce prawie nieznane, choć dziennikarze lubili podkreślać polski rodowód Starewicza ${ }^{13}$. Moim zdaniem Piękna Lukanida w równym stopniu jest filmem polskim, jak Lord Jim polską powieścią.

Traktując zbyt dosłownie Kryterium 6., można dojść do wniosku, że Max Fleischer, producent filmów rysunkowych o przygodach klowna Koko i Betty Boop, jeden z najważniejszych twórców animacji XX w., był polskim filmowcem żydowskiego pochodzenia, a zarazem pionierem polskiego filmu rysunkowego, 
ponieważ urodził się w 1884 r. w Krakowie jako dziecko Aarona Wolfa Fleischera i Malki z Pałaszów ${ }^{14}$. Na ziemiach polskich spędził pierwsze cztery lata życia, zanim rodzina wyemigrowała do Nowego Jorku. Historia animacji zna więcej takich sytuacji. Argentyński pionier Quirino Cristiani był z pochodzenia Włochem (duchowo mocno związanym z krajem swego dzieciństwa), ale na próżno szukać jego sylwetki w historii kina włoskiego. To samo dotyczy innego ważnego pioniera - Jamesa Stuarta Blacktona, który urodził się w Anglii, ale od dziesiątego roku życia mieszkał w USA, gdzie nakręcił wszystkie swoje filmy. Słusznie więc uchodzi za filmowca amerykańskiego.

Kryterium 7. wydaje się arbitralne i niekorzystne dla wielu zaproponowanych tu narracji, ale pomaga ominąć przeszkody, takie jak „emigracja talentów”, zmiana obywatelstwa lub granic państwowych.

\section{Kryterium 8.: pierwszy dystrybuowany film Kryterium 9.: pierwszy profesjonalny film (kryterium instytucjonalne)}

Powszechnie uważa się, że film musi mieć widownię. Dopiero jako wydarzenie społeczne nabiera znaczenia i wchodzi w krwiobieg historii kina. Taśma zamknięta w szufladzie ma taką samą wartość jak powieść w rękopisie. Dobrym przykładem odnalezione po latach animowane filmy Aleksandra Sziriajewa z lat 1906-1909. Ten baletmistrz Teatru Maryjskiego w Petersburgu realizował na własny użytek technicznie doskonałe filmy lalkowe i rysunkowe (na długich wstęgach papieru), ukazujące tancerzy w ruchu oraz układy choreograficzne. Przez kilkadziesiąt lat taśmy leżały ukryte w archiwum i dopiero w 2008 r. po raz pierwszy pokazano je publicznie w trakcie festiwalu Giornate del Cinema Muto w Pordenone. Gdyby trafiły do dystrybucji w chwili powstania, zagroziłyby pozycji Starewicza, Cohla oraz innych pionierów animacji z tego okresu. Jako wprawki realizowane w nie do końca jasnym celu nie miały wpływu na innych filmowców, nie doczekały się recepcji ani miejsca w dziejach kina animowanego. Ich upublicznienie w zasadzie niczego nie zmieniło - dalej pozostają nieznane. Sziriajew stoi poza czasem i historia ${ }^{15}$ - pisał David Robinson.

Kryterium braku publiczności oraz braku profesjonalizmu kierowano się w polskim filmoznawstwie przez kilka dekad. Andrzej Kossakowski pisał, że przed wojną film animowany nie istniat jako liczace się zjawisko, ponieważ nie było w kraju ani jednego twórcy, który by miał jakiekolwiek poważniejsze doświadczenia warsztatowe w tym zakresie, po drugie - nie było żadnej, ani dobrej, ani złej tradycji rodzimej, do której można było nawiazać stawiając pierwsze kroki ${ }^{16}$. Zgodnie z tą wykładnią dopiero po wojnie udało się stworzyć warunki do powtórnych - a zarazem właściwych - narodzin animacji jako sztuki.

W cytowanym zdaniu pobrzmiewają echa sporów politycznych z lat 40 . Po wojnie władza próbowała zaszczepić przekonanie, że cała historia polskiego filmu zaczyna się po 1945 r. Mówił o tym Stanisław Albrecht w trakcie Zjazdu w Wiśle w 1949 r., a jego wystąpienie opublikowano później w opiniotwórczej „Kuźnicy”: Kinematografia polska pozbawiona wszelkich tradycji artystycznych, niemal zupetnie nieposiadająca postępowego dorobku (...), stanęła po wojnie dosłownie na początku drogi $i^{17}$. Wcześniejsze dokonania przekreślono jednym ruchem jako bez- 
wartościowe, a w zasadzie - nieistniejące. W wypadku filmu aktorskiego ta retoryka nie mogła się przyjąć, ponieważ widzowie zbyt dobrze pamiętali przedwojenne szlagiery, a poza tym część kopii zachowała się. W odniesieniu do krótkich form filmowych zapanowała w tej kwestii milcząca zgoda, a żaden z pionierów nie upomniał się o należną mu rangę, zwłaszcza że dwaj najważniejsi - Starewicz i Kowańko - przebywali na emigracji. Już od 1946 r. w prasie filmowej forsowano pogląd, że nie było w przedwojennej Polsce żadnych osiągnięć w dziedzinie animacji, przygotowując tym samym grunt dla pokolenia nowych pionierów ${ }^{18}$.

Mimo to kontekst polityczny uważam za marginalny. Ważniejsze wydaje się to, jak Kossakowski rozumie genezę kina animowanego w Polsce. Jego podejście koresponduje z głośną teorią André Gaudreaulta i Philippe’a Mariona, którzy postawili tezę, że każde medium rodzi się dwa razy: najpierw jako rozszerzenie znanych form przekazu albo wariacja na temat istniejących "gatunków rozrywki", a następnie jako zjawisko odrębne ${ }^{19}$. Po drodze musi przejść proces instytucjonalizacji oraz wykształcić swój własny ,język".

Taka perspektywa nie jest obca historykom kina animowanego. Przejście od „ożywionych rysunków”, będących częścią kina atrakcji, do odrębnego "gatunku", w ramach zinstytucjonalizowanej kinematografii, opisał Philippe Gauthier $^{20}$. Zwrócił on uwagę, że jeszcze w drugiej dekadzie XX w. terminem stop pictures opisywano zarówno filmy animowane, jak i trikowe, ponieważ animacja uchodziła za rozbudowany trik. Widzowie zaś nie znali bądź nie rozumieli działania technik animacji, ponieważ wcześni pionierzy celowo strzegli tajników warsztatu, wychodząc z założenia, że ujawnienie ich zburzy iluzję, pozbawi ich twórczość pierwiastka nowości. Podręcznikowym przykładem są kreacje Starewicza, który lubił przedstawiać się jako treser owadów albo profesor genetyki ${ }^{21}$.

Kristian Moen uważa, że właściwe „wynalezienie” animacji jako medium wiąże się dopiero z działalnością studia Johna Randolpha Braya z połowy pierwszej dekady XX w., co oznacza przesunięcie „punktu zero” na osi czasu o kilkanaście lat w prawo. Przełom polegał na upowszechnieniu nowej kultury produkcji (celuloidy, etapowy proces, standaryzacja) i dystrybucji (serie i dodatki do głównego seansu); zmienił się ponadto status animacji jako rozrywki odrębnej od kina „,żywej akcji”. Jak pisze Moen: Bray odegrat kluczowa rolę w stworzeniu technologicznej i komercyjnie opłacalnej bazy dla [produkcji] filmów animowanych. Z drugiej strony, jego podejście do animacji było kombinacją różnych idei oraz możliwości tej formy, łączac sztukę i przemyst, kino i rysunki, a także wyobraźnię i naturalny ruch ${ }^{22}$. Powtórne narodziny medium, zakończone na początku lat 20. XX w., zwiastuje zalew artykułów wyjaśniających działanie technik animacji. Starewicz przestaje być treserem owadów. Niestety, praca jest naprawdę niestychanie skrupulatna, drobiazgowa i męcząca - mówi w wywiadzie, w którym opisuje cały proces realizacji filmu lalkowego, zarzucając swojego rozmówcę liczbami, szczegółami technicznymi oraz fachową terminologią ${ }^{23}$.

Te same kryteria można zastosować w opisie początków polskiej animacji, która po okresie amatorskich eksperymentów z ożywionymi rysunkami zyskała tożsamość, widownię, nową bazę produkcyjna, nowe cele, opiekę państwa, a także zastrzyk idei artystycznych, co zaowocowało w krótkim czasie sukcesami w kraju i za granicą. Jubileusz 70-lecia polskiej animacji opierał się na takich właśnie prze- 
słankach (Kryterium 9. i 10.), ale błędnie pojętych, jako że proces instytucjonalizacji kina animowanego wcale nie nastąpił w latach 40.

Kiedy zatem film animowany wyłonił się w Polsce jako nowa forma rozrywki? Wiele dowodów wskazuje na to, że wskutek kulturowego i gospodarczego zacofania proces ten przesunął się do początku lat 30. Jeszcze w połowie lat 20 . w odniesieniu do animacji z reguły używano terminów „humoreska”, „groteska”, ,igraszka trickowa”, ,film trickowy”, ,humorystyczny film trickowy” lub po prostu „dodatek” i „nadprogram”. Pod tymi określeniami - podobnie jak w wypadku pojęcia stop picture - mogły się kryć zarówno filmy rysunkowe (np. braci Fleischerów), lalkowe (Starewicza), kino atrakcji w typie mélièsowskim, jak i komedie slapstickowe, a nawet reklamy, filmy fantastyczne i dzieła niemieckiego ekspresjonizmu ${ }^{24}$. Nie znalazłem ani jednego artykułu popularnonaukowego lub wywiadu z początku lat 20., który wyjaśniałby, jak działa technika animacji i czym film animowany różni się od filmu aktorskiego lub trikowego (pewnym wyjątkiem jest Dziesiąta Muza Irzykowskiego, ale o tym później). Dopiero na granicy lat 20. i 30. następuje przełom. Ukazują się liczne teksty na temat procesu realizacji filmów rysunkowych, publikowane w prasie fachowej, codziennej, a nawet w czasopismach dla dzieci. Pojawiają się szkice teoretyczne, których autorzy próbują zrozumieć język animacji, a nawet zrekonstruować historię tej młodej dyscypliny (omawia się m.in. dokonania prawdziwych pionierów: Winsora McCaya i Émile’a Cohla).

W 1937 r. publicysta „Filmu” mógł z czystym sumieniem napisać te oto znamienne słowa: dzisiaj przy wspaniałej technice kolorystycznej i rysunkowej tych małych arcydzieł smaku i gustu (...) nie można ich [tj. filmów rysunkowych] nazywać "kreskówkami", bo to brzmi równie anachronicznie, jakbyśmy film dźwiękowy nazwali przezroczem $^{25}$. W tym czasie animacja nie była już „ożywionym rysunkiem” ani „igraszką trickową", lecz zjawiskiem dobrze rozpoznanym przez środowisko krytyków i filmowców.

Ponadto istnieje kilka dowodów, że przedwojenne animacje były dystrybuowane. Najwięcej wątpliwości budzą filmy Kuczkowskiego. Przede wszystkim brakuje śladów recepcji w prasie lub archiwaliach. Nawet z chaotycznych i mitotwórczych wspomnień autora Flirtu krzesełek jasno wynika, że większość filmów, które zrealizował (z wyjątkiem reklam), nie została upubliczniona albo że pokazywano je w gronie znajomych i współpracowników. Najbardziej intrygujące tytuły pozostały w sferze projektów bądź zostały (rzekomo) zniszczone w trakcie wywoływania, tak więc nie widział ich nawet Kuczkowski.

O filmach pozostałych pionierów mamy więcej informacji. Dzięki recenzji w "Nowinach Codziennych” wiemy, że Pan Twardowski Kowańki był wyświetlany jako nadprogram w kinie "Casino" przed filmem Na fali wspomnieñ ${ }^{26}$. Zachowały się również dowody na publiczne projekcje Kwiatu paproci i Przygód Puka ${ }^{27}$. Wcześniejszy film Kowańki, reklamowy Skarb na srebrnym globie (1932), był z kolei pokazywany prawie we wszystkich większych kinach w Czechosłowacji jako propaganda dla tamtejszych kas oszczędności ${ }^{28}$. Otrzymał nawet nagrodę w branżowym konkursie.

Najciekawsze w tym zestawieniu są losy filmu Za króla Krakusa. Wersja z 1947 r. jest tak naprawdę remakiem filmu z 1939 r., który uchodził za niedokończony, choć tak naprawdę przed wybuchem wojny zdążył się odbyć jego pokaz prasowy, po którym pewien krytyk pisał o „małym arcydziele”, zachwycając się 
profesjonalną formą tej lalkowej miniatury ${ }^{29}$. W latach 40 . Wasilewski realizował swój powtórny debiut fabularny w podobnych warunkach jak przed wojna, czyli mając do dyspozycji prywatne mieszkanie, starą kamerę, dwa reflektory i chałupniczy warsztat. Trudno również zgodzić się z przeświadczeniem Kossakowskiego, że nie istniała przed wojną tradycja, do której można się było odwołać po 1945 r. W praktyce większość filmów z lat 40. jest przedłużeniem (pod względem tematyki, kultury produkcji, technik, stylów) tendencji przedwojennych ${ }^{30}$. Rewolucja artystyczna dokonała się dopiero w połowie lat 50 .

\section{Kryterium 1o.: symboliczny początek lub pierwsze sukcesy artystyczne}

Wystawa towarzysząca obchodom 70 lat polskiej animacji w trakcie Festiwalu Filmów Fabularnych w Gdyni w taki oto sposób tłumaczyła przypadającą rocznicę: Prawdę mówiac, polska animacja narodziła się znacznie wcześniej, choć nie filmy sa tego dowodem, a... myśl. Już trzy dekady po narodzinach kinematografu Karol Irzykowski (...) wysoko ocenit możliwości artystyczne kina animowanego, prorokując mu świetlana przyszłość. Jednakże pierwsze polskie animacje stanowiły raczej zaprzeczenie teorii i przewidywań Irzykowskiego. Plansza informuje dalej, że idee Irzykowskiego wcielono w życie po 1956 r. Początek polskiej animacji jest więc rozumiany jako początek kina artystycznego, a nie pierwsze użycie techniki lub zainicjowanie produkcji.

To podejście nie jest polską specyfiką. Podobna dyskusja dotyczy kinematografii naszych południowych sąsiadów. Mimo że w latach 30. powstała w Czechosłowacji znaczna liczba filmów animowanych (zarówno reklamowych, jak i fabularnych), jubileusze liczy się najczęściej od 1945 r., w którym założono studio Bratři v triku. Tam bowiem powstały filmy, które przyniosły czechosłowackiej animacji uznanie na całym świecie. Forsując wykładnię „,nowego początku”, świadomie przekreślano związki między okresem przedwojennym a powojennym. A były one bezsprzeczne. Jak dowiodła Eva Strusková w znakomicie udokumentowanej monografii, już w latach 30. Irena Dodalova opracowata wyjątkowy program europejskiej animacji oraz pomogła stworzyć koncepcję, która przyczyniła się do powołania po wojnie studia Bratři v triku ${ }^{31}$.

Podstawowa trudność wiąże się z oceną osiągnięć artystycznych przedwojennych animatorów. To prawda, że kreskówki z lat 30. odwoływały się z reguły do stylistyki disnejowskiej, będącej na pozór zaprzeczeniem idei Irzykowskiego, ale w tamtym czasie styl ten konotował awangardowe skojarzenia; nie uchodził jeszcze za synonim kiczu i komercji. Filmy rysunkowe Walta Disneya sa niezmiernie rzadkim w praktyce filmowej przykładem połaczenia cech artystycznych z popularnościa pisał Eugeniusz Cękalski w "Pionie”. - Komedie rysunkowe ciesza się wielkim uznaniem publiczności - a jednocześnie stanowia dość pokaźna pozycje w filmowym ruchu awangardowym $^{32}$. Dopiero w latach 50., gdy do głosu doszły nowe tendencje w kinie animowanym, zaczęto definiować film artystyczny w opozycji do amerykańskich kreskówek. W latach 30. nikt tak jeszcze nie myślał. Być może więc, że petnometrażowy film Disneya, który jest przede wszystkim manifestacją technicznej dojrzałości kinematografii rysunkowej, otworzy w dziejach sztuki filmowej epokę kina malarskiego - pisał dziennikarz "Gazety Polskiej” o Królewnie Śnieżce (1937) ${ }^{33}$. Jego zdaniem właśnie ziściła się przepowiednia z Dziesiątej Muzy. 
Irzykowski bywa często traktowany jako patron polskiej szkoły animacji, który przewidział, że przyszłość filmu rysunkowego należy do malarza-poety34. To zdanie jest ważnym argumentem dla zwolenników Kryterium 10. Irzykowski uznał bowiem, że animacja to kino jutra, które wymaga formacji intelektualno-artystycznej - takiej, jaka powstanie po 1945 r. Podobnie mogli myśleć animatorzy w latach PRL-u. Jak pisał w 1960 r. Jan Lenica: rozszerzenie pojęcia "film rysunkowy" albo lepiej "film animowany", które przeczuwał Irzykowski, następuje właściwie dopiero dzisiaj (...) ${ }^{35}$. Irzykowski pisał zaś o animacji autorskiej, która uwolni się od presji ekonomicznej, wchodząc w dialog ze sztukami plastycznymi i filozofią. Filmowcy debiutujący po 1945 r. mieli więc prawo czuć się namaszczeni przez autora Dziesiątej Muzy.

Ale Irzykowski jako teoretyk filmu animowanego bywa czasami nieuważnie czytany - narzuca mu się bowiem poglądy człowieka współczesnego, który wie, jak przebiega ewolucja od „ożywionych rysunków” do animacji. Ponieważ to nie miejsce na polemikę, chciałbym tylko zwrócić uwagę, co moim zdaniem wynika z uważnej lektury Dziesiątej Muzy. Rozprawa Irzykowskiego, pisana na początku lat 20. (a w niektórych fragmentach dużo wcześniej), to cenne świadectwo przemian w dziedzinie sztuki animacji, która na Zachodzie właśnie przeszła proces instytucjonalizacji; w Polsce zaś - była dopiero na progu wielkich przemian. Irzykowski, choć wybiega myślą w przód, dostrzegając artystyczny potencjał filmu rysunkowego, nie do końca rozumie istotę tej odmiany kina, ponieważ jej nie zna jako widz. Pisze o swoim wyobrażeniu. Z kart jego rozprawy jasno wynika, że widział głównie trikowe reklamy, a o prawdziwych filmach animowanych jedynie czytał. Jednocześnie przewiduje - jakby napisali Gaudreault i Marion - „powtórne narodziny medium", które tę istotę zdefiniują raz na zawsze. Tymczasem lokuje film rysunkowy $\mathrm{w}$ tradycji kina trikowego, burleski, a nawet niemieckiego ekspresjonizmu. W przykładach, które wymienia, mieszają się bowiem filmy, które współczesny historyk przypisałby do różnych kategorii. W jego książce nawet $G a-$ binet doktora Caligari wkracza już w dziedzine filmu rysunkowego. W słowniku Irzykowskiego określenie „kino malarskie”, które zostaje przeciwstawione „kinu zwykłemu"36, oznacza zarówno film animowany, jak i kino reżyserów, którzy „wierzą w obraz". Warto dodać, że w recenzji z 1925 r., późniejszej niż Dziesiąta Muza, wspominając prawdopodobnie film z serii Out of the Inkwell Maksa Fleischera, Irzykowski pisze, że jest to "mały film trikowy”, i tak też zresztą traktuje ożywiony rysunek na ekranie - jako efekt specjalny ${ }^{37}$.

Z drugiej strony, Irzykowski - oczytany w literaturze obcojęzycznej krytyk o niezwykłej przenikliwości umysłu - dostrzega odrębność techniki poklatkowej, z zaciekawieniem obserwuje narodziny nowej tradycji w ramach kina czystej kreacji. Podejmuje również próbę zrozumienia języka filmu rysunkowego. To nowe zjawisko artystyczne nazywa raz „filmem rysunkowym”, raz „filmem przyszłości”, a raz „kinem malarskim”, ponieważ nie wie jeszcze, jak dużym zjawiskiem będzie „ożywiona plastyka”, gdy proces narodzin się zakończy. Co ciekawe, Irzykowski nie ogranicza filmu animowanego do technik poklatkowych, choć ostatecznie warunek ten zostanie uznany za sine qua non. Teorii Irzykowskiego nie można zatem sprowadzić do prognozy sukcesów polskiej animacji po 1945 r. Dziesiąta Muza stanowi koronny dowód na to, że w latach 20. film animowany dopiero zyskuje nową tożsamość, przestając być "trikiem”, stop picture oraz ekranową magią. Irzykowski uchwycił moment graniczny. 
Kryterium 10. mimo wszystko wydaje się kuszące, o dużym ładunku perswazyjnym, dlatego łatwo usprawiedliwić wszystkich, którzy się nim posługują. Historia kina lubi nowe początki i drugie narodziny. W zasadzie cała historia animacji została zbudowana na retoryce przełomu, dlatego Émile Reynaud - konstruktor praksinoskopu, a następnie dyrektor i operator Teatru Optycznego (1892) - uchodzi zazwyczaj za ostatniego reprezentanta tzw. prehistorii kina, a nie pierwszego filmowca lub pierwszego animatora, mimo że „ożywiał” na ekranie ruchome obrazy wykonane klatka po klatce. Jak pisał Donald Crafton: Choć jego świetlne pantomimy wyprzedzity kinematograf o kilka lat, pokazy Reynauda powinno się umieszczać na końcu historycznego momentu XIX-wiecznej intermedialności, kiedy wiele popularnych form spektaklu funkcjonowało obok siebie. Teatr Optyczny był technologia rozwijajaca sie na jednej ścieżce, kino - na drugiej ${ }^{38}$. Symboliczną granicę ustawiono bowiem albo w 1895 r., albo - jak chcą zwolennicy Kryterium 9. - na początku lat 20.

Ponadto logika jubileuszy rządzi się swoimi prawami. Nie organizuje się ich przecież po to, by świętować początki zjawiska, które zainicjowała filmowa reklama wątpliwej jakości lub zaginiona kreskówka będąca podróbką Disneya. Jubileusze to dobry moment, by przypomnieć sylwetki p raw d zi w y ch pionierów, obejrzeć raz jeszcze przełomowe filmy albo napawać się narodową dumą z osiągnieć a r t y s t y c z n y ch, które dostrzegła zagranica. Jak pisała Raffaella Scrimitore w książce na temat początków włoskiej animacji: Jeśli przyjąć powszechne rozumienie słowa "pionier", które zakłada dążenie do zdobywania nowych doświadczeń $w$ danej dziedzinie, możemy z pewnościa uznać owych [tj. włoskich] animatorów za pionierów; natomiast w szerszej perspektywie musimy przyznać, że zabrakło im wizjonerstwa i umiejętności w zakresie promocji. (...) W tym sensie nie było we Włoszech prawdziwych pionierów, ponieważ żadnemu animatorowi nie uda się, przynajmniej do lat 40., przetrzeć szlaku dla przyszłych pokoleń filmowców. I chociaż wartość artystyczna niektórych z tych pierwszych filmów nie budzi najmniejszych watpliwości, na próżno doszukiwać się w nich zalą̇̇ów przyszłego rozwoju produkcji ${ }^{39}$. Taka argumentacja pozwala deprecjonować osiągnięcia przedwojennych pionierów polskiej animacji. Zgodnie z Kryterium 10. nie byli to prawdziwi pionierzy, ponieważ ich filmy nie wywarły żadnego wpływu na rozwój tej odmiany kina, czego już nie można powiedzieć o powojennych wi zjo ner a ch, takich jak Lenica i Borowczyk, którzy przetarli nowy szlak. Z drugiej strony, jak próbowałem udowodnić, to samo kryterium dowodzi, że symboliczny przełom - polegający na poczuciu narodzin nowej formy artystycznej - nastąpił w latach 30. XX w.

\section{Wnioski: od kiedy?}

Zarówno początki animacji na świecie, jak i w obrębie narodowych kinematografii zostały ukształtowane w narracji historycznofilmowej pod wpływem wielu krzyżujących się kryteriów, co oznacza, że nie ma jednej obiektywnej interpretacji. Czasami najważniejsze kryteria łączą się, tworząc jednoznaczny obraz. Francuzi nie mają wątpliwości, że ich pionierem był Émile Cohl. Rosjanie muszą zaś wybrać pomiędzy Starewiczem i Sziriajewem.

Obchody 55-, 60- i 70-lecia polskiej animacji opierały się głównie na Kryterium 10. (z dodatkiem 4., a czasami również 8. lub 9.), co oznacza, że istnieją podstawy, by pogodzić się z budzącym kontrowersje jubileuszem, zwłaszcza że 
widownia przyzwyczaiła się do rocznicowego rytmu. Warto podkreślić, że pierwsza rocznica, z 2004 r., została zorganizowana w dobrej wierze przez Stowarzyszenie Filmowców Polskich, po to aby przypomnieć wybitne osiągnięcia polskich animatorów: od Wasilewskiego do Bagińskiego ${ }^{40}$. Dzięki rocznicowemu budżetowi klasyka polskiej animacji, głównie z czasów PRL-u, wróciła do kin w dziewięciu polskich miastach. Było to wydarzenie bez precedensu. Nikt chyba nie przeczuwał, jak wielkim sukcesem zakończą się obchody 55-lecia, które zostały zainicjowane pod wpływem impulsu (i z prawie dwuletnim poślizgiem). Rozgłos tej imprezy sprawił, że nie dało się poprzestać na jednostkowym wydarzeniu. Dlatego sztafeta trwa.

Nieszczęśliwie na herolda symbolicznego początku wybrano film, który już w 1947 r. mógł się wydawać anachroniczny, zakorzeniony w tradycji przedwojennej. Nie ma on nic wspólnego ani z ideami Irzykowskimi, ani nowymi tendencjami w sztuce animacji lat 40. Co gorsza, nie jest to pierwszy film animowany po 1945 r., gdyż poprzedzają go wstawki, reklamy, „ożywione” diagramy oraz fabularny Lis Kitaszek (1946) Macieja Sieńskiego, który - na przekór czarnej legendzie o niedopuszczeniu filmu do dystrybucji - był w Polsce rozpowszechniany dwa razy: przez krótki czas w 1946 r. (prawdopodobnie cofnięto go, ponieważ raził słabą stroną warsztatową), a po dwóch latach w parze z filmem pełnometrażowym, a więc dla szerokiego kręgu widzów ${ }^{41}$. Niewykluczone, że artystycznie dorównywał Krakusowi. Zgodnie z Kryterium 10. można zatem świętować okrągłe rocznice polskiej szkoły animacji zainicjowanej przez takie filmy, jak Był sobie raz... (1957) i Dom (1958) Jana Lenicy i Waleriana Borowczyka. Gdyby wsłuchać się w retorykę jubileuszów 60- i 70-lecia polskiej animacji, okaże się, że tak naprawdę fetowano złote lata polskiej szkoły, a nie najstarszych pionierów, którzy pojawiają się zwykle na marginesie. Albo wcale.

Przede wszystkim jednak nie sposób dłużej udawać, że przed wojną film animowany w Polsce nie istniał. Po prostu długo czekał na swoich adwokatów. Niestety, żaden z filmów fabularnych z lat 30. prawdopodobnie nie ocalał, choć istnieje nadzieja, że się odnajdzie ${ }^{42}$.

Od jubileuszu 55-lecia polskiej animacji wiedza na temat pionierów zmieniła się diametralnie. Jak na ironię, w zbiorowej książce Polski film animowany (2011), wydanej jako pokłosie 60-lecia, znajduje się starannie opracowany rozdział autorstwa Marcina Giżyckiego, który jako pierwszy przywraca znaczenie przedwojennym pionierom ${ }^{43}$. Rocznice - nawet te źle wyliczone - odegrały ważną rolę w promowaniu polskiej animacji w kraju i na świecie, z pewnością przyczyniając się do wzrostu zainteresowania tematem przez filmoznawców. Miały więc wpływ na weryfikację mitów ukształtowanych jeszcze w latach 70., ale teraz, pod presją nowych faktów, należałoby przemyśleć logikę jubileuszy. To korzystny czas na zmianę perspektywy. Dwudziestolecie międzywojenne cieszy się obecnie dużym zainteresowaniem historyków. Kolejne publikacje przywracają pamięć o zapoznanych zjawiskach kultury masowej tej epoki, dlatego początków jazzu, komiksu, nowoczesnego projektowania graficznego doszukujemy się w latach 20. i 30., a nie - jak onegdaj - w okresie powojennym.

Reasumując, trzy konkurencyjne i bardziej uzasadnione merytorycznie daty dla 1947 r. to przełom 1916 i 1917 r. (Kryterium 1., 2., 5., 6.), czyli pierwsze próby filmowe Feliksa Kuczkowskiego, który wymyślił „film wizyjny” i podjął próbę urzeczywistnienia tej idei; rok 1934 (Kryterium 4., 8., 9.), kiedy pierwsze polskie 
animowane filmy fabularne weszły na ekrany i trafiły do publiczności. Kompromisem byłby początek lat 30. XX wieku (Kryterium 2., 3., 4., 8., 9., 10.) - nieuchwytny moment, w którym kończy się proces instytucjonalizacji filmu animowanego w Polsce, rozpoczyna produkcja i poważna refleksja krytyczna. Jak na ironię, kompromis wydaje się najbardziej uzasadniony merytorycznie, ale zupełnie niepraktyczny. Trudno według niego planować jubileusze.

${ }^{1}$ E. Strusková, The Dodals: Pioneers of Czech Animated Film, tłum. L. Vidmar, NFA, Prague 2013, s. 17.

${ }^{2}$ C. Russett, R. Starr, Experimental Animation: An Illustrated Anthology, Van Nostrand Reinhold, New York 1975, s. 75.

${ }^{3}$ G. Bendazzi, Cartoons: One Hundred Years of Cinema Animation, tłum. A. Taraboletti-Segre, Indiana UP, Bloomington 1994, s. 11.

${ }^{4}$ M. Cook, Early British Animation: From Page and Stage to Cinema Screens, Palgrave Macmillan 2018, s. 65.

${ }^{5}$ F. Kuczkowski, Wspomnienia o filmie przyszłości, maszynopis w arch. Filmoteki Narodowej - Instytutu Audiowizualnego (dalej: FINA), sygn. A-129.

${ }^{6}$ D. Crafton, Emile Cohl, Caricature and Film, Princeton UP, Princeton 1990, s. 129.

${ }^{7}$ D. Crafton, Preface, w: T. de Vries, A. Mul, "They Thought it was a Marvel" Arthur Melbourne-Cooper (1874-1961). Pioneer of Puppet Animation, Amsterdam UP, Amsterdam 2009, s. 13.

${ }^{8}$ Zob.: W. Starewicz, Plastyka ożywiona (La Plastique Animée), tłum. W. Jewsiewicki, „Film na Świecie” 1984, nr 307-308, s. 27; F. Kuczkowski, dz. cyt.

${ }^{9}$ Polskie filmy rysunkowe z roku 1918! Rozmowa ze Stanisławem Dobrzyńskim, pionierem polskiego filmu rysunkowego, „Wiadomości Filmowe" 1934, nr 23, s. 7.

${ }^{10}$ Wkraczamy na nowe tory! Oto pierwszy polski film makietowy, „Kino” 1931, nr 36, s. 10.

${ }^{11}$ G. Strøm, Caricatures, Cartoons and Advertisements: The Pioneers of Nordic Animated Film, w: Nordic Explorations: Film before 1930, red. J. Fulerton, J. Olsson, J. Libbey 1999, s. 133.

${ }^{12}$ A. Deriabin, Wiertow i animacija. Roman kotorowo nie było, „Kinowiedczeskije zapiski” 2001, nr 52, www.kinozapiski.ru/ru/article/sendvalues/809/ (dostęp: 13.11.2017).

${ }^{13}$ Por. P. Sitkiewicz, Uczony i czarodziej. Zmienne koleje losu mistrza Starewicza, "Images” 2015, t. 17, nr 26.

${ }^{14} \mathrm{R}$. Pointer, The Art and Inventions of Max Fleischer: American Animation Pioneer, McFarland \& Co., Jefferson 2017, s. 7.
${ }^{15}$ D. Robinson, Alexander Shiryaev: Dance to Film, „Film History” 2009, nr 21, s. 301.

${ }^{16}$ A. Kossakowski, Polski film animowany 1945-1974, Ossolineum, Wrocław 1975, s. 15.

17 S. Albrecht, Walka o film, „Kuźnica” 1949, nr 49, s. 3. Wersja drukowana wystąpienia została złagodzona.

${ }^{18}$ Zob.: Z. P. [Z. Pitera], W królestwie dwóch Guliwerów, „Film” 1946, nr 1, s. 7; (p) [Z. Pitera], Pierwsze kroki... „Film” 1946, nr 6, s. 5.

${ }^{19}$ A. Gaudreault, P. Marion, A medium is always born twice... ,Early Popular Visual Culture" 2005, t. 3, nr 1.

${ }^{20}$ P. Gauthier, A Trick Question: Are Early Animated Drawings a Film Genre or a Special Effect?, "Animation" 2011, t. 6, nr 2.

21 Y. Tsivian, The Case of the Bioscope Beetle: Starewicz's Answer to Genetics, "Discourse” 1995, t. 17, nr 3.

${ }^{22}$ K. Moen, Imagination and Natural Movement: The Bray Studios and the "Invention" of Animated Film, "Film History” 2015, t. 27, nr 4, s. 146.

${ }^{23}$ J. Wyszomirski, Człowiek, który ożywia lalki, „Naokoło Świata” 1927, nr 44, kolumny 67-70 .

${ }^{24}$ Podaję na podstawie reklam oraz informacji repertuarowych z prasy lat $20 . \mathrm{XX} \mathrm{w}$.

${ }^{25}$ S. Felix, Na moim ekranie, „Film” 1937, nr 28/1, s. 1.

${ }^{26}$ T. P-ski, "Na fali wspomnień" w kinie "Casino", „Nowiny Codzienne” 1934, nr 231, s. 2. A. Bohdziewicz (Dziś i jutro polskiego filmu, „Życie Sztuki" 1935, s. 221) w oficjalnym sprawozdaniu informuje, że film został zatwierdzony przez cenzurę.

27 Zob.: A. Czermiński, Zapomniana "Calinka”, „Czas” 1938, nr 24, s. 7; J. Radzimiński, Lwowscy filmowcy przy pracy, "Światowid" 1934, nr 9, s. 17.

${ }^{28}$ Polski film propagandowy w Czechosłowacji, „Kino” 1932, nr 28, s. 10.

${ }^{29}$ D. Kohl, Nowy film kukiełkowy, ,Wiadomości Filmowe" 1939, nr 15, s. 9. Legendę filmu nieukończonego stworzył sam Wasilewski, który pisał, że film miał być gotowy w listopadzie 1939 r., ale wojna przerwała pro- 
dukcję (tenże, Moja droga do filmu lalkowego [maszynopis], arch. FINA, sygn. A-62, poz. 102). Być może wersja pokazana w sierpniu nie była jeszcze skończona, choć relacja dziennikarza tego nie potwierdza.

${ }^{30}$ Zob. P. Sitkiewicz, Polska szkoła animacji, słowo/obraz terytoria, Gdańsk 2011, s. 56-57.

${ }^{31}$ E. Strusková, dz. cyt., s. 348.

32 (c) [E. Cękalski], Radosna godzina Mickey Mouse, „Pion” 1934, nr 37, s. 8.

${ }^{33}$ Beta, W sprawie filmu rysunkowego, "Gazeta Polska" 1938, nr 277, s. 13.

${ }^{34}$ K. Irzykowski, Dziesiąta Muza. Zagadnienia estetyczne kina, Krakowska Spółka Wydawnicza, Kraków 1924, s. 215.

${ }^{35}$ J. Lenica, Duch w lampie, "Projekt” 1960, nr 4, s. 17.

${ }^{36}$ K. Irzykowski, dz. cyt., s. 214.

${ }^{37}$ K. Irzykowski, Kurier kinowy, „Wiadomości Literackie" 1925, nr 15, s. 5.

${ }^{38}$ D. Crafton, The Veiled Genealogies of Animation and Cinema, "Animation” 2011, t. 6, nr 2, s. 101.

${ }^{39}$ R. Scrimitore, Le origini dell'animazione italiana. La storia, gli autori e $i$ film animati in Italia 1911-1949, Tunué, Latina 2013, s. 27. Z włoskiego przełożył Łukasz Latopolski.
${ }^{40}$ Chciałbym podziękować dr Annie Wróblewskiej za pomoc w ustaleniu kulis obchodów rocznicy z $2004 \mathrm{r}$.

${ }^{41}$ Znalazłem kilka niezbitych dowodów w prasie codziennej. Np.: (ty), Dziewięć godzin przed ekranem, „Express Wieczorny” 1946, nr 127, s. 3; Pierwszy polski film rysunkowy w 34 programie aktualności, ,Robotnik” 1948, nr 182; (zg), "Moja miła”. Film radziecki, „Dziennik Bałtycki” 1948, nr 213, s. 4.

${ }^{42}$ Od pani Agaty Zalewskiej dowiedziałem się, że Filmoteka Narodowa ma w depozycie fragmenty 6 filmów Jana Jarosza, których nie może odrestaurować z powodów prawnych oraz trudności technicznych. Ponadto rozmawiałem z człowiekiem, który trzymał w ręku fragment kliszy z Wyprawa myszy na tort Włodzimierza Kowańki, będącej w posiadaniu rodziny filmowca. Niestety, trop się urwał.

${ }^{43}$ M. Giżycki, Przed 1945: prekursorzy i pionierzy, w: Polski film animowany, red. M. Giżycki, B. Zmudziński, Polskie Wydawnictwo Audiowizualne, Warszawa 2008.

\section{Paweł Sitkiewicz}

Historyk kina, medioznawca, profesor Uniwersytetu Gdańskiego. Zajmuje się historią kina animowanego w Polsce i na świecie, kulturą filmową dwudziestolecia międzywojennego oraz prehistorią komiksu. Autor czterech książek: Małe wielkie kino. Film animowany od narodzin do końca okresu klasycznego (2009), Polska szkoła animacji (2011), Miki i myszy. Walt Disney i film rysunkowy w przedwojennej Polsce (2012) oraz Goraczka filmowa. Kinomania w międzywojennej Polsce (2019). Współautor leksykonu Powieści graficzne (2015) pod redakcją S. J. Konefała.

\section{Bibliografia}

(c). [Cękalski, E.] (1934). Radosna godzina Mickey Mouse. Pion, (37), s. 8.

(p). [Pitera, Z.] (1946). Pierwsze kroki.... Film, (6), s. 5.

[b. a.] (1931). Wkraczamy na nowe tory! Oto pierwszy polski film makietowy. Kino, (36), s. 10.

[b. a.] (1932). Polski film propagandowy w Czechosłowacji. Kino, (8), s. 10.

[b. a.] (1934). Polskie filmy rysunkowe z roku 1918! Rozmowa ze Stanisławem Dobrzyńskim, pionierem polskiego filmu rysunkowego. Wiadomości Filmowe, (23), s. 7. 
[b. a.] (1948). Pierwszy polski film rysunkowy w 34. programie aktualności. Robotnik, 182.

Albrecht, S. (1949). Walka o film. Kuźnica, (49), s. 3.

Bendazzi, G. (1994). Cartoons: One Hundred Years of Cinema Animation (thum. A. Taraboletti-Segre). Bloomington: Indiana UP.

Beta (1938). W sprawie filmu rysunkowego. Gazeta Polska, (77), s. 13.

Cook, M. (2018). Early British Animation: From Page and Stage to Cinema Screens. New York - London: Palgrave Macmillan.

Crafton, D. (1990). Emile Cohl, Caricature, and Film. Princeton: Princeton UP.

Crafton, D. (2011). The Veiled Genealogies of Animation and Cinema. Animation, 6 (2), Ss. 93-110. https://doi.org/10.1177/1746847711404979

Czermiński, A. (1938). Zapomniana „Calinka”. Czas, (24), s. 7.

Deriabin, A. (2001). Wiertow i animacija. Roman kotorowo nie było. Kinowiedczeskije zapiski, 52. www.kinozapiski.ru/ru/article/sendvalues/809/

Felix, S. (1937). Na moim ekranie. Film, 28 (1), s. 1.

Gaudreault, A., Marion, P. (2005). A Medium is Always Born Twice.... Early Popular Visual Culture, 3 (1), ss. 3-15. https://doi.org/10.1080/17460650500056964

Gauthier, P. (2011). A Trick Question: Are Early Animated Drawings a Film Genre or a Special Effect?.Animation, 6 (2), ss. 163-175. https://doi.org/10.1177/1746847711407624

Giżycki, M. (2008). Przed 1945. Prekursorzy i pionierzy. W: M. Giżycki, B. Zmudziński (red.), Polski film animowany. Warszawa: Polskie Wydawnictwo Audiowizualne.

Irzykowski, K. (1924). Dziesiata Muza. Zagadnienia estetyczne kina. Kraków: Krakowska Spółka Wydawnicza.

Irzykowski, K. (1925). Kurier kinowy. Wiadomości Literackie, (15), S. 5.

Kohl, D. (1939). Nowy film kukiełkowy. Wiadomości Filmowe, (15), s. 9.

Kossakowski, A. (1975). Polski film animowany 1945-1974. Wrocław: Ossolineum.

Lenica, J. (1960). Duch w lampie. Projekt, 4.

Moen, K. (2015). Imagination and Natural Movement: The Bray Studios and the "Invention" of Animated Film. Film History, 27 (4), ss. 130-150. https://doi.org/10.2979/filmhistory.27.4.130

Pointer, R. (2017). The Art and Inventions of Max Fleischer: American Animation Pioneer. Jefferson: McFarland \& Co.

P-ski, T. (1934). „Na fali wspomnien”” w kinie „Casino”. Nowiny Codzienne, (231), s. 2.

Radzimiński, J. (1934). Lwowscy filmowcy przy pracy. Śriatowid, (9), S. 17.

Robinson, D. (2009). Alexander Shiryaev: Dance to Film. Film History, 21 (4), ss. 301-310.

Russett, R., Starr, C. (1975). Experimental Animation: An Illustrated Anthology. New York: Van Nostrand Reinhold.

Scrimitore, R. (2013). Le origini dell'animazione italiana. La storia, gli autori e i film animati in Italia 1911-1949. Latina: Tunué.

Sitkiewicz, P. (2011). Polska szkoła animacji. Gdańsk: słowo/obraz terytoria.

Starewicz, W. (1984). Plastyka ożywiona (La Plastique Animée) (thum. W. Jewsiewicki). Film na Śriecie, (307-308), ss. 27-28.

Strøm, G. (1999). Caricatures, Cartoons and Advertisements: The Pioneers of Nordic Animated Film. W: J. Fulerton, J. Olsson (red.), Nordic Explorations: Film before 1930. John Libbey.

Strusková, E. (2013). The Dodals: Pioneers of Czech Animated Film (thum. L. Vidmar). Prague: NFA. 
Tsivian, Y. (1995). The Case of the Bioscope Beetle: Starewicz's Answer to Genetics. Discourse, 17 (3), ss. 119-125.

ty. (1946). Dziewięć godzin przed ekranem. Express Wieczorny, (127), s. 3. Vries, T. de, Mul, A. (2009). "They Thought it was a Marvel": Arthur Melbourne-Cooper (1874-1961). Pioneer of Puppet Animation. Amsterdam: Amsterdam UP. Wyszomirski, J. (1934). Człowiek, który ożywia lalki. Naokoło Świata, 44. Z. P. [Pitera, Z.] (1946). W królestwie dwóch Guliwerów. Film, (1), s. 7. zg. (1948). „Moja miła”. Film radziecki. Dziennik Bałtycki, (213), s. 4.

Keywords:

Polish animation;

Polish cinema; origins of animation; Polish animated film

\begin{abstract} Paweł Sitkiewicz When Does Polish Animation Begin? A Filmological Investigation

The paper refers to the $55^{\text {th }}, 60^{\text {th }}$ and $70^{\text {th }}$ anniversaries of Polish animation, celebrated in 2004, 2007, and 2017, respectively. The author tries to answer the essential questions: When did Polish animation actually begin? Why is the pre-war period omitted in historical reflection? He discusses ten most common criteria used by historians of animated cinema around the world to describe the origins of animation in their countries. All criteria are adapted to Polish conditions and applied to films produced from 1917 to 1957. As a result, the author proposes a revision of the jubilees organized since 2004. At the same time, he attempts to understand the arguments of those film historians who say that the beginning of the Polish animation is, after all, marked by the 1947 premiere of Zenon Wasilewski's puppet film za króla Krakusa (King Krakus).
\end{abstract}

